\title{
In Defense of an Error: Intellectual Corruption in Contemporary Science
}

\author{
James F Welles* \\ East Marion, New York, USA \\ *Corresponding author: James F Welles, East Marion, New York, USA
}

Received: 海 December 10, 2018

Published: 監December 17, 2018

\begin{abstract}
A reviewer of a book I wrote claimed an idea presented therein could be found elsewhere. Nine years later, no one could say where, but no one would correct the erroneous claim, so what began as an effort to obtain a redress of a legitimate grievance slowly degenerated into a tour deface of a surreal ethics warp in our intellectual community. The citations submitted to document the claim failed to do so, and the file on the dispute maintained by the American Psychological Association (APA) really is not about my case at all. The University of Connecticut (UConn) and the American Association for the Advancement of Science (AAAS) failed to hold anyone accountable. There was a basic conflict between the conduct of officials of all these organizations and their ethical codes. In a culture of intellectual corruption, behavior consisted of a pervasive and extended cover-up characterized by sophistry, secrecy, fantasy, irrelevance, rationalization, misattribution, misrepresentation, fabrication, falsification, failure to communicate and an adamant refusal to deal logically and fairly with the facts of the case. This demonstrated a complete lack of cognitive integrity and constituted a total betrayal of the academic/scientific commitment to truth.
\end{abstract}

\section{Introduction}

In September 1993, my book Understanding Stupidity (US) was reviewed by Dr. Thomas O. Blank of The School of Family Studies at the University of Connecticut in Contemporary Psychology (CP), a journal of reviews sponsored by the American Psychological As-sociation. Although all reviews are subjective, and reviewers have a right to be critical, this was very harsh and, in some ways, unprofessional. I availed myself of the opportunity to respond in the "Point/Counterpoint" format graciously provided to aggrieved authors by the journal. This consisted of a four-part exchange of statements between me and Dr. Blank and appeared in the May 1994 issue. In his last comment, to which I had no opportunity to reply in print, he alleged my challenge to Darwinian psychology that "Normal human behavior is not necessarily adaptive"[1] could be found somewhere other than in my book. The intellectual importance of the idea that "Normal is not necessarily adaptive" is difficult to overstate because all the life sciences are based on the Darwinian concept that normal is adaptive. That is, any species-specific characteristic be it anatomical, physiological, behavioral, or whatever is automatically assumed to be adaptive. Occasionally, an abnormality may also be adaptive, in that a new development can be even better suited to the environment than the norm, but the converse, that the norm may be maladaptive, would commonly be regarded as heresy by any-one nurtured on Darwin. Although evolutionary psychologists Cosmides \& Tooby (1987) have explained how genetically influenced human behavioral mechanisms shaped by natural selection for past environmental conditions may produce maladaptation in our contemporary, rapidly changing surroundings, their work merely suggests the possibility that normal human behavior may not be adaptive: They do not break with Darwin and explicitly make this point. In my book, I show that self-reinforcing, maladaptive cultural norms characterize human conduct, and if someone else has made this point in print, as Dr. Blank alleged, no one has been able to tell me who it was and when and where it was published. I received an advanced statement of Dr. Blank's allegation and twice challenged him in writing (March 19 and April 2) to say where my idea could be found without receiving even the courtesy of a reply. I then turned to the APA and beginning with CP editor Dr. John Harvey presented my case to a succession of officials all to no effect. In a letter to me of Apr. 12, 1994, Dr. Harvey adopted an odd and vapid standard of 
judgment for the case by claiming not that Dr. Blank's statement was valid but that he had fulfilled his obligations to the journal [2].

When dealing with the others in this matter, I would generally acquaint an individual with the basics of the case and then ask the party to help resolve the matter by securing for me one of two things in print-the idea I had expressed or a correction of the error. With the APA's credibility squarely on the line, of-ficials would not deal with the facts of the case and could not substantiate the published statement. Some presumed to do so, and in an e-mail to me on April 22, 1999, Dr. Vanden Bos actually claimed five had succeeded although their attempts all failed to withstand even the most cursory objective scrutiny. The best he could come up with was a citation of a book by Prof. J. C. Coleman which presented some examples showing my idea is valid but not that he nor anyone else had published it. He discussed ego-defense mechanisms and some presumably normal developmental problems-like sleep disorders-which can be construed as non or maladaptive if the reader is so inclined. Obviously, it is axiomatic that there must be examples existent upon which a generalization like mine is based [3], but Prof. Coleman did not pull the specifics he cited together [4] as I had done and induce a generalization from them (or expand to generalization from one of them) about normal human behavior possibly not being adaptive. The next best case is even more mystifying because it is based on an example of abnormal human behavior being maladaptive. It is a citation of Dr. Sigmund Freud (1904) discussing the type of slips of speech which reveal the speaker's mind. Such slips are incredibly rare and could not possibly be construed as normal by any reasonable person, but nonetheless that is what the APA did. Some people might go years without making such a slip; the aver-age person might make one such slip per year out of millions of words uttered. However, this rarity-and therefore, irrelevancy was erroneously cited and accepted by the APA as normal [5] and somehow the intellectual equivalent of my global, overarching, universal generalization about all of normal human behavior. By far the most ambitious if selfdefeating effort was a reading list of books Dr. Blank sent me in a letter of August 26, 1994. I had just commenced an eventually futile effort to get officials at UConn to hold him accountable according to their explicitly stated by-laws, but his dean did prevail upon him to send me the letter presumably by convincing him that he could not just stonewall: He had to send me something-even if it proved him wrong. This was the sole communication I ever received from him regarding this matter.

The centerpiece of the letter was a list of ten books (with no page numbers) which demonstrated Dr. Blank's inability to document the claim he had made in print. Rather than even attempting to do so, he made a patronizing, substitute claim-that my idea is a central element in several theoretical approaches to psychology. It is central to understanding psychology because it is a fundamental principle of human behavior, but if it plays a role in a number of theoretical approaches to psychology, one must wonder how considering it has never appeared in print. Actually, all he did was presume to back up one fallacious claim with another and, with the burden of proof squarely on him, presented not a shred of evidence to support either. However, his ersatz claim was really just a red herring and irrelevant to the issue in dispute which was: Where else did someone present my idea in print? On Sept. 1, I asked him again to tell me who had done so and where it could be found; again, he did not reply, presumably because he could provide no valid reference. Even though it is irrelevant, Dr. Blank was wrong even in implying that my idea is a central theme in any of the books listed [6]. They deal with psychopathology, psychodynamics, perception, information processing and communication, but while they are concerned with psychic shortcomings, my idea is mentioned in none of them. Each indicates the mind is less than perfect in some way, but although Dr. Blank concluded this implies maladaptation can be normal [1], the authors did not. Each dealt with a piece of the elephant of maladaptively, but being good Darwinian psychologists, none related this to normal behavior nor fashioned it into any theme or theory whatsoever. As incredible as it seems, Dr. Blank listed two books which flat-out contradict his case. These are explicitly organized on the principles that psychological processes and perception are adaptive, yet he cited them as supporting his erroneous claim that one can access elsewhere my idea that normal human behavior might be maladaptive. I made photocopies of the appropriate pages, underlined the relevant passages and, on Sept. 16 , sent them to him with the hope he would provide a reference, with a page number, documenting his case. As usual, he did not respond. I could not find nor has anyone been able to show me a single statement in any of the listed books which could possibly be taken to document Dr. Blank's claim. Indeed, the only relevant comments I could find totally undercut him and show the authors' position to be the exact opposite of what he alleged. In the total absence of any statement supporting Dr. Blank and in the presence of statements contradicting him, Dr. Vande n Bos nevertheless spuriously claimed the list documented his allegation.

The next weakest case cited was a letter to me, in Aug. 1995, in which Dr. Bruce Overmier provided some references for the idea that normal learning may lead to maladaptive behavior. He himself conceded these were simply off the point under consideration (i.e., irrelevant) as they dealt with the ontogeny rather than the adaptiveness of normal human behavior. Oddly, the weakest and oddest of these case was provided by Dr. Vanden Bos himself. In a phone conversation (June 6,1994), he averred that as co-author of a book he had used my idea when de-veloping the notion that normal behavior and schizophrenia are on a continuum-i.e., polar opposites. Of course, his undocumentable, ex post facto claim of this non sequitur was of no value whatsoever in terms of showing where my idea could be found in the scientific literature [7].

Nearly a year after Dr. Vanden Bos erroneously claimed five people had successfully dealt with the problem, a sixth failed when Dr. Merry Bullock, Associate Executive Director for Science, 
responded to my phone call to her on Mar. 13, 2000, regarding the case. In an e-mail to me three days later, she provided a number of examples from psychology and physiology which demonstrated that my idea is valid and of far reaching significance, but she did not show anyone else had published it, which is what the APA was supposed to be doing. Finally, Prof. Don Dewsbury of the University of Florida provided some citations explaining that maladaptive human behavior could be the result of set systems mismatched with new conditions that is, behavior resulting from psychological mechanisms shaped in the Pleistocene interacting with stimuli from the contemporary, rapidly changing technological environment. Those cited did not claim this insight applied to normal behavior, and although in the context provided and considering the nature of the examples given, a reader might so construe it, it was not a conclusion reached by the authors nor a point they explicitly made. This was fairly typical for some committed to claiming documentation of the equation "Normal human behaviormaladaptive": Someone would find a comment about one side of the equation (e.g., an explanation for maladaptation), complete it in his own fevered mind and then creatively (mis)attribute the whole, muddled concoction to the writer. However, careful reading of these citations showed no universal generalization clearly and explicitly linking normal human behavior with maladaptation [8]. The psychic mechanisms discussed could just as plausibly be producing abnormal, vestigial or just plain fluky behavior which was maladaptive, so these hardly constituted valid references for Dr. Blank's allegation. Although all these citations were perfectly useless for documenting Dr. Blank's allegation, they did provide his defenders with not so much what they needed [9] but, more important, what they wanted: Something they could call references [10]. This was truly neurotic-a complete breakdown of rationality, a denial of reality and an indulgence in fantasy comprehensible only if one under-stands that the mental world of Dr. Blank's APA supporters had become a "Verbal reality" as convincingly deceptive as the vaunt-ed "Virtual reality" of cyberspace. Over a period of over nine years, thirty officials and functionaries of the APA sent me some eighty written communiques. They could not document Dr. Blank's claim, would not ask him to do so nor explain why they would not ask. This failure to supply and, worse yet, determined refusal to request documentation convinced me the APA was not only unable but, worse yet, unwilling to resolve this matter properly. Indeed, if there was one constant in the conduct of APA officials in this regrettable af-fair, it was that no one abided by much less enforced the organization's Ethical Principles of Psychologists and Code of Conduct, the preamble of which calls upon psychologists to be fair, promote integrity, aspire to the highest possible standards of conduct, be concerned about the ethical compliance of their colleagues' conduct and work to develop a valid and reliable body of scientific knowledge. Of course, it mattered to no one in the organization, including the Office of Ethics, that administrat-or [11] and staffers made an absolute mockery of these aspirational goals so nobly set forth in the idealized if effete, superegoish Ethics Code.
This indifference if not hostility to accuracy was revealed early and repeatedly in the deliberate, persistent misrepresentation of my complaint by Dr. Vanden Bos. This was all the more surprising because I had specified the idea to be documented in a letter to him of June, 30,1994, only to have him ignore this basic issue in his response to me on Aug. 1. I then clarified the matter in my response of Aug. 8. Nevertheless, his return letter of Aug. 26 evinced an enduring misconception as to the nature of my case. Ergo, on Aug. 30 , in a letter that went unanswered, I spelled out once again the precise nature of my complaint-what it was and was not-and naively assumed he would drop the false case which seemingly persisted in his mind and deal thenceforth with my case as I had repeatedly presented it to everyone in all cor-respondence [12].

Because of the vague way APA loyalists have of writing, it took me five years to realize he had done no such thing. Rather, he had deliberately, knowingly and wittingly maintained his own fallacious case about the issue of originality in general as dealt with in the review itself. He did so although I had never raised that issue, twice explicitly so informed him and likewise twice made clear what my complaint was about-the particular idea mentioned by Dr. Blank in his last P/C-point statement. I concluded Dr. Vanden Bos was deliberately wrong about this whole affair and was consciously committed to doing everything he could to avoid doing what was right. I came to this realization as a result of the comments made in Prof. Overmier's e-mail to me of July 7. I assume but do not know that Dr. Vanden Bos was made aware of my reply, but Prof. Overmier, as a member of the APA's Board of Directors, certainly could have called for the organization to deal with my complaint as such. Obviously, he never did. This was confirmed by a remark made by Dr. Vanden Bos in response to a request by Mr. Charles Rozier of "Accuracy in Media" to comment on this dispute. In keeping with Dr. Vanden Bos's un-conscionable, tendentiously erroneous stance on the matter, he indicated there was no rational basis for my complaint because (in his fantasy world) I had had two opportunities to deal with "The issue" in print-which would have been true if my case were the one, he had created. However, as I had twice informed him in writing and repeated to Prof. Overmier, my case was about a comment Dr. Blank made in his last P/C-point statement, to which I had no opportunity whatsoever to respond in print. Ever the diplomat, I certainly would not want to call Dr. Vanden Bos a liar, so, rather, let me point out what he said was not true, and he had known it was untrue for the previous seven years. In sum: Drs. Blank, Overmier and Vanden Bos simply would not deal with my complaint-preferring to deal with Vanden Bos's contrived version instead.

The net result of Dr. Vanden Bos's clever if unprincipled conduct was a fifteen-inch-thick file compiled by the APA over a period of nine years which was not about my complaint at all! Reviews of it and decisions based on it were irrelevant to resolving this matter but could be and were improperly used for dismissing what was incorrectly perceived and referred to as my case [13]. 
Clearly, the efforts and years wasted due to this con-fusion over the nature of my complaint must be laid completely at the APA's door. By 2001, Dr. Vanden Bos and Prof. Overmier had known for seven and two years respectively of the discrepancy between my case and the APA's but regrettably both lacked the ethical commitment and intellectual integrity to resolve the matter by correcting the known error. The APA also made a mockery of basic intellectual standards by maintaining a case based on a premise officials knew to be fallacious. The one thing no one in the organization would do was build a case based on the facts. This demonstrated a cynical disregard for the most elemental essential of science: A commitment to the truth. With my only hope for a proper resolution of my case depending on the truth being acknowledged by an authority of intelligence and integrity at the APA, my effort was doomed from the start. I could find no such person because such people do not rise to the top in professional scientific organizations in which the distortion of information is deemed acceptable. Consistently in this case, deliberately obtuse officials acted not to correct an obvious error but to protect the person who had made it. From presidents on down, the commitment was to social bonding with ev-eryone at best indifferent to accuracy, at least accepting of in-souciance and at worst arrogantly opposing the truth. If anyone was concerned that an error had been made, it was to see that it was not corrected and that neither the one who made it nor those who would not correct it would be held accountable [14]. To the ex-tent this case is indicative, the APA may be likened to an intellectual Black Hole which sucks up facts and truth but from which no light emerges or likened to the Catholic Church in the early 1500's-an institution thoroughly corrupts morally and intellectually [15]. If more support for that assertion is needed, consider the rev-elations resulting from Board of Directors member Dr. Overmier's review of the APA file. He examined it in the APA's central offices in Washington in June 1999, and on July 7 sent me a 1,800 word e-mail detailing his reasons for concluding no correction was in order-although I had explicitly warned him that the APA freely indulged in misinformation and misattribution and all but begged him to check back with me to be sure he had the facts straight before making such a decision. Fortunately, in stating his reasons, he revealed the incomplete and truly corrupt nature of the file as well as the unprofessional biases of those (for whom he spoke) who reviewed it, whatever it was. According to his misguided impressions, I had failed to ask for what I wanted and had made a false charge. However, upon scrutiny, these assertions proved to be both irrelevant and fallacious as I indicated to him the next day in a nine-page reply making (among others) the points presented below. He did not respond. Upon reviewing the file, Dr. Overmier concluded that if there was a failure in this matter it was not the APA's but mine because I failed to ask for what I wanted in the first place. I found this utterly incomprehensible. Apparently, there was no failure by Dr. Blank for publishing an invalid statement, no failure by anyone in the APA to document the erroneous claim and no failure to correct it.
Theoretically, when a possible error is reported to a journal editor, there really is only one appropriate response-determine whether there was in fact an error. This is done by the editor requesting validation of the disputed statement. Once the existence of the error is determined, there are a number of possible proper responses-with a published correction and apology at the top of the list-but leaving the error uncorrected is not one of them. However, the editor must decide which course of action to take, and any ambivalence in this regard on the part of the person reporting the error cannot possibly be used to justify failing to determine whether or not an error had occurred. (The APA's position would be like that of law enforcement failing to investigate a reported case of police brutality because the victim had allegedly not been clear as to what the sentence should be if the accused colleague were eventually found guilty.) Nevertheless, in reality, that is exactly what APA officials did. Not wanting to deal with the matter, they conjured up a scenario to rationalize "Freezing". They used the contention that I had not asked for what I wanted in the first place as an excuse to do nothing at all when their course of action really was to-tally independent of me and my requests-that is, what I wanted really did not matter: What mattered was whether or not Dr. Blank's allegation was valid. However, there was another minor problem with their scenario: I had asked for what I wanted in the first place. On the day I received an advanced copy of Dr. Blank's final statement (Mar. 19, 1994-in fact early enough for him to have changed his final comment before the May issue of CP closed), I sent him a letter asking him to document his allegation and predicting he would not do so [16] because no reference for it exists. I was right: He did not because, I maintain, he could not. Indeed, he did not even have the professional courtesy to respond to the letter. Hence, Dr. Overmier's analysis that this constituted a failure on my part was totally, absolutely, $100 \%$ incorrect. There certainly was a failure, but it was on the part of APA reviewer Dr. Blank for failing to alter his comment, document his published allegation, as I asked him to do, or even answer his mail.

As for Dr. Overmier's other major rationale for deciding that no correction was in order-i.e., his contention that my charge my originality had not been challenged until Dr. Blank's final Point /C-point statement was not true, OK: I must concede that the charge as stated is not true. Hypothetically, if the charge were false, there would appear, at first glance, to be only one other possibilitythat my origin-nality (i.e., uniqueness) had been challenged earlier, and indeed it had been, but so what? Even if the general topic of originali-ty had been dealt with before Dr. Blank's last statement, was the APA therefore justified in ignoring the issue of the invalidity of his last remark in the Point/Counterpoint exchange? Did the fact that the topic of originality had been broached and I had told the truth about it before granting him a license to make a fallacious statement in his last comment to which I had no opportunity to reply? Clearly not, but that nevertheless was the APA's position on the matter [17]. Two paragraphs above, I conceded that the charge 
my originality had not been challenged until Dr. Blank's last remark was in fact not true. Having pointed out that, even so, he had no right to publish misinformation on the topic, I now raise another minor issue: I never made that charge. What I had hammered at repeatedly to the exclusion of every other related issue-was that he had falsely alleged my specific idea about normal human behavior not necessarily being adaptive could be found somewhere other than in my book, and I merely called upon him to specify where.

Although the APA insisted on confusing matters in order to rationalize its policy of doing nothing, my case was remarkably simple, unidimensional and just. For the sake of clarity, let me say what it was not: It was not about the general issue of originality, nor did I ever even imply much less state that Dr. Blank's allegation was the first challenge thereto. My case dealt simply, directly and explicitly with his erroneous assertion that a particular idea of mine could be found somewhere other than in my book. Obviously, someone at the APA inflated my singular com-plaint into a generality, fallaciously equated that creation with previous general statements and then unjustifiably dismissed it [18]. However, Dr. Blank's final comment was different in nature from his earlier generic, subjective comments about my alleged lack of originality in that its specificity lent it to the intellectual standard of verification. As a skeptical author, I had quite properly called upon him (and his supporters) to document his claim, but no one could. This-my actual case about the invalidity of Dr. Blank's allegation-clearly was misrepresented in the file, which artfully misled reviewers mistakenly to think I had said his last remark was the first challenge to my originality when I had done no such thing. The reason I did not is that Dr. Blank's disputed comment was not a challenge (first or otherwise) to my general originality at all-although administrators at the APA, for their own machia-vellian motive, insisted on dealing with it as if it was: It was simply a challenge to the uniqueness of but one of my specific ideas. However, indulging in fantasy, they fabricated and then threw out a case conveniently created just for that purpose and then claimed they had dismissed my case when they really had not even dealt with it. Throughout my travails with this organization, I had been victimized by misattribution, but with this, the APA had taken betrayal to a new low, the level of an intel-lectual crime, the scientific equivalent of falsifying a charge if not actually tampering with evidence.

Although Dr. Blank and the APA always acted as if we had different perceptions of the same story, this is emphatically not a matter of two parties having different sides of the same story: It is a case of two different stories entirely. The APA's deals with the issue of originality in general which was raised in the body of the review and to which I could have responded in the P/C-point exchange had I chosen to do so, but I did not. Mine is that Dr. Blank made an invalid allegation in his final statement in the $\mathrm{P} / \mathrm{C}$-point exchange when he incorrectly averred a particular idea of mine could be found somewhere other than in my book. These are two different issues completely, and as time passed it became progressively clearer to me that no one could document the erroneous, published claim and that no one would correct it. The faulty nature of the Blank/ APA case became crystal clear in a series of exchanges between Dr. Blank and a Mr. Les Stacy, who wrote him in Oct. 2002 regarding this matter. Dr. Blank revealed in a letter of the 17 th a basic weakness in his case when he emphasized his reliance on Dr. Vanden Bos as champion of his cause. He erroneously characterized Dr. Vanden Bos as "the person who as most directly addressed the matter..." to members of the APA and public. Apparently, Dr. Blank was unaware of the fact that Dr. Vanden Bos has never directly addressed this matter (i.e., my complaint) at all to anyone. Indeed, he was the one who deliberately altered the nature of the dispute so as to deflect attention away from my actual complaint and to the ersatz case he duplicitously concocted.

In addition, in the same letter, Dr. Blank vaguely referred to some references which he and the APA believed "provided him (sic) [meaning me] various sources and ideas that [Dr. Blank] and then they felt made similar points about the inevitability and necessity of maladaptive as well as adaptive behaviors...." What he failed to mention was that none of these references was or even claimed to be about normal behavior. Basically, they showed that behavior can be maladaptive. Well, Duh! That was hardly the issue in dispute as Dr. Blank well knew from the letters, I had written him. The issue is whether someone else said (in print) that normal human behavior is not necessarily adaptive. It is irrelevant that he and others dealt with the inevitability/necessity of mal/adaptive behavior. It would be relevant and accept-able if someone made the point I made in similar or indeed any wording whatsoever, but it is totally irrelevant if someone deals with similar but different topics which are not at issue. Dr. Blank also made the point that UConn administrators advised him he had "long since" fulfilled [his] responsibilities, presumably meaning to the university, although its Laws and By-Laws explicitly require faculty members to be accurate $(\mathrm{XV}, \mathrm{A}, 3)$ and foster and defend intellectual honesty $(\mathrm{XV}, \mathrm{A}, 4)$. His statement in the final $\mathrm{P} / \mathrm{C}$-point comment clearly was inaccurate, and he did nothing in this case to foster much less defend intellectual honesty. Nor did anyone I dealt with at UConn. I did think some-one might hold him accountable according to the by-laws, but I did not at any time, in any way urge university officials to discharge him, as apparently someone falsely alleged to him. Basically, a social rather than academic ethic prevailed, and no one would hold him accountable for his unconscionable conduct. He also referred inaccurately to my (web)site, of which I have none. He might be forgiven for this as my books do appear on a website, but it is not mine. He could have found this out had he bothered, but a commitment to accuracy is not his forte. In a fit of unwarranted righteousness, Dr. Blank continued that EVERY (caps his) person who reviewed the case sided with him, and they did. However, he failed to mention that not a single one of those supporters ever saw much less dealt with my complaint. They all reviewed the ersatz 
case deliberately created by Dr. Vanden-Bos to mislead readers to a desired rather than a correct conclusion. Further, Dr. Blank repeated the canard that every official and venue I appealed to has said he had discharged his responsibility as a reviewer appropriately, and he was presumably right-they most likely did say that: It just was not true. If you think otherwise, bear in mind that none of the criteria of responsibility he cited appears in the Guidelines for $\mathrm{CP}$ Reviewers. Alas, the first sentence under the heading "Content of the Review" states that CP aspires to "scholarly excellence". Another call for scholarship is made in the context of the reviewer as a critic, and in the last paragraph, the reviewer is called upon to "make a contribution to the scholarly advancement of psychology". Just how a critic who published a documentable (i.e., false) statement can be judged to have discharged his obligation to scholarly excellence and the scholarly advancement of psycho-logy is beyond me. Not surprisingly, these specified guidelines go not only unheeded but unmentioned by Dr. Blank. Finally, he ends the letter with a sketch of all the coverage of the dispute and opines it has been more than adequate. Naturally, he failed to mention that despite all the more than adequate coverage, no one ever documented his false claim.

In a following e-mail on the 28th, Dr. Blank wrote: "this is not a matter or misunderstanding but a profound difference of opinion about the significance and potential impact of 'US' and subsequently about whether or not the materials I provided as the basis for my conclusion expressed in the review and in the 'P/C-point' that followed are or are not adequate to support those conclusions." Incredibly, what this passage reveals is that this matter was indeed one of misunderstanding albeit perhaps willful specifically, that after nine years of controversy Dr. Blank allegedly had no idea as to what it was all about. It was most emphatically NOT about the significance and potential impact of the book etc., as quoted above. After all the letters I had written him (see p. 8 above), Dr. Blank feigned he did not even know the controversy was about the invalidity of his specific allegation in his final P/C-Point comment that a specific idea of mine could be found somewhere other than my book. Now that is implausible if not literally incredible-as in "Impossible to believe". To put this entire matter another way, the APA's position would have been perfectly valid had Dr. Blank's final comment in the P/C-point exchange been just another generic, diffuse, subjective swipe at my alleged general lack of originality, but it was not. However, in order to justify the predetermined policy of the APA of not holding an errant colleague accountable by publishing a correction, officials feigned otherwise. This was thoroughly un-professional and dispels the myths that the APA labors in behalf of psychology, that science is a self-correcting institution and that truth prevails.

To appreciate the absurdity of this, consider the following conclusion which is implicit, if not stated, in the APA's rationalizing: “Because Dr. Welles's charge that this was the first challenge to his originality was found to be untrue we will not correct Dr. Blank's error". This suggests a mentality more des-perate than professional.
Certainly, I have made my share of mistakes in life, but I did not make the mistake alleged by Prof. Overmier, and even if I had done so in a letter to the APA would that justify leaving Dr. Blank's published error uncorrected? Of course not, but nevertheless, it remains uncorrected largely because of a non sequitur based on an invalid statement misattributed to me. (No one ever checked to see if I made the statement cited: Nor need I wonder who concocted it.) Is it not indeed odd that a charge which was never made was analyzed and scrutinized and found to be untrue, but Dr. Blank's published statement was never verified by anyone in the APA or anyone else for that matter? In the face of their inability to document his claim and their unconscionable unwillingness to publish an appropriate correction, these fair-minded professionals (who in principle aspire to be guardians of psychology, promoters of integrity, molders of science, creators of knowledge and purveyors of truth) did the next best thing-they unilaterally, summarily and unjustly declared the unresolved matter closed. To be fair, correcting an error should be as easy as publishing it in the first place, but, au contraire, the APA evinced a nearly pathological resistance to my assertion that an error had been published. Striking by its presence on the part of the APA administrators was the double standard used to judge information depending upon its purpose or source: Every statement made sup-porting Dr. Blank was accepted at face value without any skepticism, scrutiny or vetting whatsoever while virtually every statement of mine was dismissed out of hand as merely self-serving. In terms of veracity, nothing was required of Dr. Blank at any point while my challenge to his erratum was brusquely dis-missed by fabrication and misattribution, so his misstatement could remain uncorrected. In contrast to the lax indifference to the publication of his invalid comment, every difficulty, obstacle and impediment-ranging from ignoring what I did say to fabricating fallacious things I did not-was placed in my way to get someone to set the record straight. Equally striking by its absence on the APA's part was the scientific practice of objective verification: To my great regret (but presumably to the satisfaction of the APA), nothing anyone wrote was validated by factual analysis [19]. In failing to document or correct Dr. Blank's claim, APA officials evinced a shocking indifference to inaccuracy; when dealing with my complaint, they demonstrated an active hostility to truth. This hostility apparently precluded any awareness that there never was, is not now and never will be an acceptable lead-in to the conclusion "... therefore, the error will not be corrected" for the simple reason that there is no acceptable excuse for leaving an error uncorrected. However, APA officials' desperation led them to use any lead-in to excuse the unjustifiable. The rationale seemed to be that if I had made a mistake somewhere along the line, Dr. Blank's error would not be corrected. This is, of course, absurd and also proved a nugatory strategy because I had made no substantive error in this matter. However, that fact would not stop the APA'ers: If nothing I said or wrote would suffice for their sordid purpose, erroneous statements could be (and were) created and misattributed to me. Further, without qualms, they repeatedly fabricated straws to 
grasp at and then used them to invent transparent rationalizations to avoid holding an errant colleague accountable for his obvious mistake. At least one thing became clear, however-how everyone could review the file and decide against the truth. Previously, that had been a mystery to me: How Dr. Blank could say my idea could be found elsewhere, no one could say where, no one at the APA would ask him nor explain why no one would ask, and yet everyone who read the file concluded nothing was wrong? The answer was and remains the reviewers were not evaluating my case at all. For NINE YEARS they dealt with the APA's version of my complaint which had been morphed into a fabricated, straw man case (about originality in general) specially doctored up to be moot and without merit but which definitely was not mine. To put this in a nutshell, the APA simply was not going to publish a correction regardless of the facts, logic or ethics involved in the matter. Further, nothing I said, wrote or did (or the way I said, wrote and did them) altered this policy one iota. I went to the organization seeking redress of a legitimate grievance, but since my case did not fit the APA's "Don't admit/ Don't correct" position, administrators indulged in fit of re-verse reality and concocted one that did. Presumably to their satisfaction if the detriment of psychology, my actual, specific case was lost on the reviewers, who could read the file of this peculiar organization and come away not knowing even what my complaint was. Accepting sophistry for science, they uniformly fell into line embracing official, intellectual legerdemain without scrutiny, criticism or comment. How did this happen? We may never know because the reviewers-in good APA fashion-were mostly quite guarded about what they read and even more so about how if not, why they reached decisions which were so clearly at odds with the facts and in defiance of both the APA's Ethics Code and logic; but we can speculate [20].

Perhaps they were objective scientists deceived by misinformation created by the APA and proceeding to whatever erroneous conclusion logic led them: They might have assumed the APA's file was an objective, fair, balanced repository of all relevant, valid information not knowing that it was more biased than an attorney's brief in a criminal case-more akin to a public relations scam deliberately concocted as an expert source of misinformation designed to mislead those who trusted in it. Perhaps they were partisan, biased members of a social clique looking to protect one of their own: They knew a colleague had goofed, so like thoroughly dedicated professionals, they circled the wagons. Perhaps they approached the file from the conclusion there would be no correction and then worked back from there looking for support: They found none, but not to worry, they invented some while conveniently ignoring the facts which would have led-horror of horrors-to a valid conclusion. Their phantom support was then shaped by illogical fits of mental acrobatics into rationalizations for leaving a published error uncorrected. Surely one must question the file's relevance and validity as well as the reviewers' basic intelligence, professional integrity and commitment to power over truth. Yet another takes on the odd mentality which pervaded the APA was provided by Richard McCarty, Ph.D., in a phone conversation on Mar. 20, 2000. He ventured there was nothing anyone other than the Office of Ethics could do because the APA regarded editorial independence as sacrosanct so none of the sycophantic staff could or would interfere or influence an editor committed to misinformation. This certainly was news to me, as I had spent (to that time) six years dealing with twenty-six individuals in the organization and none, not even three Chairs of the Publications \& Communications Board and as many editors of APA journals, had ever even mentioned this policy. Frankly, it smacked of a newly coined taboo specially designed to support the accompanying suggestion that I drop the matter. A further rationale was provided when Dr. McCarty informed me the matter was resolved because the organization's gamut of permissible procedures had been exhausted by its powerless staff. This would have been reasonable if running out of options re-solves a problem or had the APA's regulations, applied by dedicated scientists, led inexorably to the truth. However, the APA's regulations as applied by its ethically challenged personnel resulted in perpetuating an error-proving something was wrong with the rules and/or the administrators, who should have been living by and enforcing the rules but refused to do either. Identifying what was wrong was fairly easy because the permissible procedures included obvious, gross irregularities of commission and omission. Among the former were falsification of my claim, maintenance of a corrupt file and misattribution of fabricated fallacies to me: Among the latter-ignoring the facts of the case, failure to deal with issues I raised, refusal to answer questions I asked and, most egregiously, failure to ask for much less insist upon and obtain documentation of Dr. Blank's allegation or provide a correction. As deplorable as all this was, Dr. McCarty's position on the matter might have been understandable if not forgivable had his job been director of public relations, but all of the above was condoned, supported and presented by the APA's "Executive Director of Science" [21]. That says it all! Well, not quite all, considering President-elect Philip Zimbardo's evasive e-mail response on Feb. 11, 2001, to some relevant material I sent him. Unfortunately, the case hit a scato-logical low with his personal "Shit happens", forget it, reaction. By return e-mail, I agreed with his first point but indicated the appropriate adjoined would be "Clean it up". His return e-mail that afternoon made clear he had no intention of dealing with the matter at all much less according to the APA's aspirational goals. Oddly, his sophism for not getting involved was that no one else in the organization had done anything to resolve the problem, so there was no reason why he should, whereas it was for precisely that very reason (i.e., others had not done their jobs), that I called upon him to do his. Over a period of two days, he sent me four e-mails in which the only time he alluded to the problem was to disavow explicitly any intention whatsoever of dealing with it. He absolutely would not deal with the simple, basic fact that, in this case, shit did not just happen like a bolt out of the blue: It was created by the APA-which also had both the means and the moral 
obligation according to its own Ethics Code to clean it up [22]. In Dr. Zimbardo's evasiveness, he personified the APA's basic attitude not toward the problem it created but toward me. He devoted the major parts of his e-mails try to convince me there was something wrong with me for not accepting the status erratum as if I was seeking his professional advice on how to adjust to an imperfect world [23]. However, I was not. I was a fellow intellectual calling upon him, as an official of the APA, to correct a published error.

There was at least consistency in Dr. Zimbardo's refusal to deal with the issue: None of the APA presidents approached in this case exhibited so much as a trace of professional integrity. Indeed, it is my contention that no ethical person can become head of the APA. It is essentially a job requirement that any high-ranking officer be intellectually corrupt to the point that given a choice between promoting the short-term image of the organization or the longterm good of psychology, science and the truth, a commitment to public relations and image will prevail over that to accuracy and validity every time. Likewise, one must note the lack of integrity of UConn officials whose expressed job it was to exercise quality control over the faculty. Unfortunately as alluded to earlier, they proved all too human in their desire to maintain the ego and the unwarranted reputation of their colleague. Thus, a common psycho/social dynamic prevailed over any informational imperative commitment to academic excellence at UConn in this matter [24]. While the books on Dr. Blank's list were of no value what so ever in documenting his printed allegation, university officials were loath to deal with that basic fact, consistent in their failure to do so and all but lined up to sacrifice the functional quality of their organization for the sake of maintaining its immediate, hollow image [25]. Nor would AAAS officials hold either Dr. Blank or anyone else responsible in this matter. I conveyed to them the facts of the case and asked for an examination of the APA's unethical conduct but all to no avail [26]. On Feb. 16, 1995, the Committee on Scientific Freedom and Responsibility condoned rather than condemned the error by misconstruing (as the APA had done) its basic nature and my complaint. They trivialized the error and claimed they did not perceive the issue as I did or my complaint as important enough to concern them. However, unlike a statistical error (which can be quantified) or conceptual error (which can be subjectively graded according to size), this error is a scholarly matter of prior claim, warranted resolution in its own right regardless of any quantitative estimations and like cases of plagiarism can be properly settled only one way-documentation of the allegation by recourse to the literature. In a larger sense, the nature of my complaint called into question an essential element of the scientific process: Is science a self-correcting institution? [27] The answer from everyone involved in this unfortunate affair was a resounding, unequivocal "No". Thus did the intellectual establishment react to and render futile efforts to correct an error in the literature. Striking by its absence in everyone was a good faith effort to resolve this matter by supplying supporting evidence for a published statement. With the attitudes of all parties totally at odds with the fundamental scientific and academic goals of knowing and learning, I never did find anyone at the APA committed to psychology, at UConn to education or at the AAAS to science. The general reaction would best be characterized as "Evasive" with the basic strategies commonly invoked being denial-there was no error, trivializing-it was not a big error, falsifying-dealing with some other problem and shutting down an adamant refusal to deal with an undeniable, qualitative error in a scholarly journal and the attendant academic scandal and Kafkaesque cover-up [28]. In sum, my biggest difficulty was finding someone who would deal effectively with my complaint. No one could document Dr. Blank's statement, and yet not only would no one insist he do so, but no one in the APA or AAAS would even ask him to nor explain to me why no one would ask. It is tempting to refer to Dr. Blank's defenders and supporters as "Psychotic", since they would not deal with the reality of a published error because of perceptual exaggerations and distortions on a scale which would lead a mammologist to confuse an elephant with a mouse. It is unlikely some of them, despite their advanced degrees, were simply "Intellectually challenged" and unable to process some basic facts logically, but there was a remarkable sloppiness in their unidirectional rationalizations. Finally, it is quite reasonable to regard them as "Unethical" be-cause it was always possible someone of conscience might recognize a professional obligation to the truth, break ranks with APA [29] sycophants and make a good faith, determined, thorough effort to communicate frankly and openly and correct the obvious error.

Of the three possibilities, the last is the most difficult to overcome because those indulging in unethical conduct can use their often-considerable intellectual gifts deliberately to per-vert knowledge. In this case, rather than fostering intellectual standards, all at the APA directed their often-considerable talents and skills toward circumventing and evading such standards in the cause of a distinctly anti-intellectual agenda. Every single decision made by every single person backed the one who had erred: No one even requested much less insisted that Dr. Blank document his allegation or publish a correction [30]. There would be no redress of my legitimate grievance because in my diagenesis search for a person with intellectual integrity I could not find anyone in a position of authority and possession of the facts who would stand up for the truth and even ask much less demand verification of a published statement. Ideally, academicians base their conduct on principles of logic, evidence, morality and social concerns-meaning the impact of applied knowledge on society. However, in the real world, there is another social concern which may come into play, and that is a concern for the image and reputation of a college. Unfortunately, in this case, that concern overwhelmed any commitment by establishment officials to logic, evidence or morality. It is indeed a sad commentary on contemporary scholarship that so many wellschooled if not well-educated people could distinguish right from wrong and deliberately chose to be wrong [31]. There is a serious 
problem in science of which few are aware, and no one is addressing There is a taboo about errors in the literature-they should not be corrected. With the established mentality so unconscionably committed to personal politics over professional principles and dedicated to academic imagery over informational accuracy, there is a need for scientists and journal editors who care about the intellectual process to honor existent codes of ethics by working out concrete, functional ground rules for dealing with challenges to the veracity of their publications. When the validity of a published statement is contested, that should be taken as a cause not for cronyism and a cover-up but for documentation of the statement or correction of the error. No one committed to science, the facts and truth should expect anything else or accept anything less.

\section{Addendum}

If the APA does not have a de jury policy of refusing to correct errors, it certainly has a long, venerable tradition of failing to do so. In 1970, Professors JL Junks and David W Fulker published a paper in the APA's Psychological Bulletin on the nature and nurture of IQ. An attempt by Atam Vetta of Oxford to correct an algebraic error therein was rejected by the editor RJ Herrnstein, and in 1984, an attempt by Professor Peter Schönemann of Purdue University to correct another error of analysis and misinterpretation in the same paper was rejected by then Bulletin editor John Masters. (Hirsch, 1990). In a similar vein, the APA never corrected Cyril Burt's technical errors on the heritability of intelligence published as the lead article in the March 1972 issue of the American Psychologist. Nor did it caution readers about the use of Burt's fallacious data nor even so much as mentioned the more serious matter of the possibility of deliberate fraud. Of course, doing so would have necessarily entailed admitting an obvious factual error, which is apparently taboo at the APA [32]. This detached indifference of the APA to matters scientific was touched upon by Robyn Dawes in his letter of resignation, published in August 1988, from the organization in his opinion based on twenty-five years' experience in the APA, it failed miserably to assure that the professional practice of psychology was based on available scientific knowledge [33]. In fact, its Ethics Code, far from requiring the rational application of knowledge in practicing psychology, dealt relatively lightly with practices that ignored scientific evidence. Further, the major thrust of APA policy was primarily a public relations commitment to convince the American public that its practicing members have not only special expertise but a power that simply does not exist. Specifically, the APA concentrated on enhancing the power, status and income of member practitioners in the absence of evidence for any special expertise on their part or indeed in the face of evidence that it does not exist at all.(All emphasis his). This indifference to science, reality and reasonable procedure on the part of the APA was later evinced by its high-handed treatment of Carolyn Phinney, who had research data stolen and was defrauded of a grant while at the Institute of Gerontology at the University of Michigan in the late 1980's. The courts awarded her $\$ 1$ million eight years later, but after the APA presumed to put its spin on the affair, she was duly informed that her allegations had been dismissed by the Ethics Committee for lack of supporting evidence. This was done although she made no allegations to the Ethics Committee, was never even informed it was considering her case and was never asked to provide any evidence in her own behalf. This would be like a civil court hearing a suit between two parties, one of whom had not even been informed of the hearing, and then, in ruling against that party, saying its suit (which it had not filed in the first place) had been dismissed because no evidence for it had been presented.

If that is odd, it is outrageous that the organization would harass psychologist Dr. Elaine Heiby for testifying before the Hawaii state legislature in opposition to one of the APA's pet causes-the authorization of psychologists to prescribe drugs. Her facts and arguments were unassailable and went unchallenged, but she finally resigned from the organization in 1998 after enduring a dirty tricks/out-to-get-her tactical campaign characterized by ad hominem attacks, threats of unfounded ethics charges, cyberforgery and calls to the University of Hawaii attempting to re-strict her academic freedom. After all, she had to be taught a lesson for all to see for actively opposing a policy favored by administrators whose official code of ethics explicitly called upon them to be "Fair", of all things. For sheer intellectual cowardice, however, nothing matches the reaction of the APA to the furor resulting from the publication of Temple University's Prof. Bruce Rind et al.'s analysis of studies on childhood sexual abuse (Psyc. Bull.,1998). The conclusion that such experiences do not necessarily damage all victims was offensive to some conservatives and angered many Congressmen, all of whom were irate that millions in tax dollars were used to produce research results some of which might exculpate pedophilia. Rather than standing up for the scientific integrity of the study, the APA caved in to political pressure and distanced itself from the unwelcome conclusion, thus clearly demonstrating that, far from being a professional scientific society devoted to the truth, it is really a public relations outfit committed to its own immediate image. In the context of science, the APA lost either of two ways because if the study published was valid, it deserved support: If it was not, it should not have been published in the first place. However, in the context of Congressional relations, placating Washington politicos and conservative pundits [34] can be deemed successful, albeit to the detriment of minor considerations like psychology, science and the truth. Rather than standing up for the integrity of the scientific study, the APA caved in to political pressure and cravenly distanced itself from the authors. To make matters worse, the APA flip-flopped twice on the publication of an article submitted to the American Psychologist by Scott O. Lilienfeld about the Rind debacle. Initially, the article was accepted for publication in June 2001 by guest editor Nora Newcombe, also of Temple. Then journal editor Richard Mc-Carty overruled her decision only to have to cave in to the furor raised by the psychological community in general over the appearance of censorship of material justly critical of the 
APA's mis-handling of the Rind affair. Striking by its absence was any professional integrity by anyone of authority at the APA, which, forced to do something right, grudgingly published the piece in March 2002. Another conservative, columnist Linda Bowles (2001), noted that an APA approved booklet Just the Facts about Sexual Orientation \& Youth presented just selected facts and omitted those about the high risks and dangers of homosexuality. Likewise, the APA be-trayed its claim to be a scientific body when it hyped gay marriage and gay adoptions. It began its studies with the self-confirming belief that there is no difference between interchange-able genders, and when research indicated that gays and lesbians are not as psychologically healthy as straights, the APA dis-missed it as bias built into a homophobic society [35-37]. (Nicolosi and Nicolosi 2002.) These are but two more examples of the APA promoting its liberal social agenda at the expense of scientific objectivity but not to the point of endangering obtaining research grants from generous political conservatives. Btw, the APA Dictionary of Psychology provides a definition of intelligence but not of stupidity. And who is the editor? The ethical professional dedicated to the truth, Dr. Gary Vanden Bos.

\section{References}

1. (1992) American Psychological Association. Ethical Principles of Psychologists and Code of Conduct. American Psychologist, Washington DC, USA 47(12): 1597-1611.

2. Augustine St. The City of God, pp. 413-426.

3. Blank T(1993) Do We Have to Be So Stupid? Contemporary Psychology 38(9): 941

4. (1994) Personal communication to J Welles.

5. (2002) Personal communication to Les Stacy.

6. (2002) Personal communication to Les Stacy, Bowles L. Homosexual zealotry.

7. Broad W, Wade N (1982) Betrayers of the Truth. Simon and Schuster, New York, USA.

8. Bullock(2000) Personal communication to Welles.

9. Burt C (1972) Inheritance of general intelligence. American Psychologist 27: $175-190$.

10. Coleman J (1969) Psychology and Effective Behavior. Scott, Foresman \& Co, Glenview, IL.

11. (1995) Personal communication to J Welles.
12. Cosmides L, Tooby J (1987) From evolution to behavior: Evolutionary psychology as the missing link. In J Dupre (Edn.) The Latest on the Best: Essays on Evolution and Optimality. MIT Press; Cambridge, MA, USA, pp. 277-306.

13. Dawes R (1988) Letter of resignation printed in Ob-server 3(1): 14-15.

14. Freud S (1904) Psychopathology of Everyday Life. Mentor, New York, USA.

15. (2001) Guidelines for Contemporary Psychology Reviewers.

16. Harvey J (1994) Personal communication to J Welles.

17. Heiby E (1998) Personal communication to Arnold Lazarus.

18. Hirsch J (1990) A nemesis for heritability estimation. Behavioral and Brain Sciences 13(1): 137-138.

19. Jinks JL, Fulker DW (1970) Comparison of the Biometrical, Genetical, MAVA and Classical Approaches to the Analysis of Human Behavior. Psychological Bulletin 73(5): 311-349.

20. Johnson R (2000) FreeAPA@Excite.com.

21. Lilienfeld S (2002) When worlds collide: Social science, politics, and the Rind et al. (1998) child sexual abuse meta-analysis. American Psychologist 57(3): 176-188.

22. (2002) Personal communication to Welles.

23. Nicolosi J, Nicolosi L (2002) A Parent's Guide to Pre-venting Homosexuality. InterVarsity Press, Downers Grove, IL, USA.

24. Rind B, Tromovitch P, Bauserman R (1998) A meta-analytic examination of assumed properties of child sexual abuse using college samples. Psychological Bulletin 124(1): 22-53.

25. Thurmond D (1994) Personal communication to Mark Young.

26. Vanden Bos G (1994) Personal communication to Welles.

27. (1994) Personal communication to Welles.

28. (1999) Personal communication to Welles.

29. (2001) Personal communication to Don Dewsbury.

30. (2001) Personal communication to Charles Rozier.

31. Welles J (1994) Personal communication to Gary VandenBos.

32. (1994) Personal communication to Gary VandenBos.

33. (1999) Personal communication to Bruce Over-mier.

34. (2001) Personal communication to Philip Zim-bardo.

35. Zimbardo P (2001) Personal communication to Welles.

36. (2001) Personal communication to Welles.

37. (2001) Personal communication to Welles.

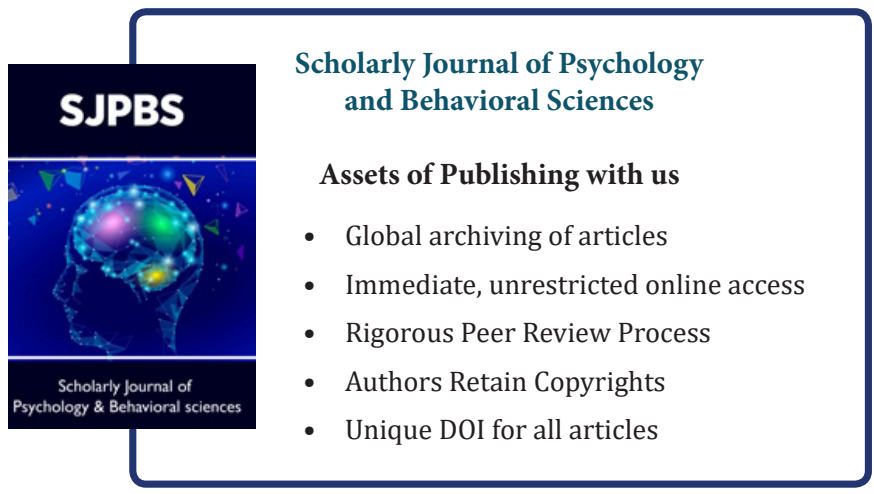

